\title{
Global Radioxenon Emission Inventory from Nuclear Power Plants for the Calendar Year
} 2014

\author{
Martin B. Kalinowski ${ }^{1}$ (D) and Halit Tatlisu ${ }^{1}$
}

\begin{abstract}
For the purpose of monitoring for compliance with the Comprehensive Nuclear-Test-Ban Treaty (CTBT), the International Monitoring System (IMS) is being established that includes 40 sensor systems for atmospheric xenon radioactivity. Its purpose is to monitor the atmosphere for signatures that may indicate a nuclear explosion. Normal operational releases of radioxenon from nuclear facilities can regularly be observed by these very high-sensitive noble gas systems. Existing best estimates of releases for a generic year are unlikely to apply for any specific year at the level of individual facilities because their releases are highly variable and can change by several orders of magnitude from year to year. In this paper, best knowledge of the radioxenon emission inventory from nuclear power plants (NPPs) is collected for the calendar year 2014. The distribution function for each CTBT relevant radioxenon isotope is derived from all releases from NPPs as reported for 2014. The data of this paper can be used for developing and validating methods based on atmospheric transport modelling that are designed to enhance understanding of the impact of known sources on the IMS background observations.
\end{abstract}

Keywords: CTBT, radioxenon, emission inventory, radionuclide monitoring, atmospheric radioactivity.

\section{Introduction}

Radioactive xenon isotopes provide the most likely observable radioactive signatures of underground nuclear explosions (Kalinowski 2011). A global monitoring system for atmospheric xenon radioactivity is being established as part of the International Monitoring System (IMS) to verify compliance with the Comprehensive Nuclear-Test-

Electronic supplementary material The online version of this article (https://doi.org/10.1007/s00024-020-02579-w) contains supplementary material, which is available to authorized users.

1 Preparatory Commission for the Comprehensive NuclearTest-Ban-Treaty Organization, Provisional Technical Secretariat, VIC, P.O. Box 1200, 1400 Vienna, Austria. E-mail: Martin.kalinowski@ctbto.org
Ban Treaty (CTBT). The atmospheric concentrations of ${ }^{135} \mathrm{Xe},{ }^{133 \mathrm{~m}} \mathrm{Xe},{ }^{133} \mathrm{Xe}$ and ${ }^{131 \mathrm{~m}} \mathrm{Xe}$ are measured.

This paper focusses on the radioxenon emission from nuclear power plants (NPP) which are measured frequently at IMS stations. Depending on the IMS location, NPPs contribute between zero and $80 \%$ of all observed radioxenon concentrations (Achim et al. 2016). Other papers cover the release of radioxenon from nuclear research reactors (Kalinowski et al. 2020) and medical isotope production facilities (Gueibe et al. 2017) in the year 2014. A few medical isotope production facilities (MIPFs) are the strongest sources but all NPPs together contribute as much as one strong MIPF (Kalinowski et al. 2014).

Radioxenon is released continuously from NPPs at low level during normal operation cycles as gaseous effluent into the atmosphere from the reactor, turbine and auxiliary building ventilation systems. The main purpose of the building ventilation systems is to confine the radiation within regulatory limits. The discharge points of radioactive gases and their activity depend on the type of reactor and its off-gas system. Delay lines and absorption mechanisms may be in place which allow for hold-back and decay in order to decrease the release of radioactivity into the atmosphere. Nevertheless, the noble gas releases cannot be completely removed from NPPs. Measurement methods of the radioactive material released in gaseous effluents from the various building ventilation and off-gas systems of NPPs are described by Kalinowski and Tuma (2009).

Kalinowski and Tuma (2009) calculate or estimate the radioxenon emission for all existing nuclear power plants (NPPs) in a generic year based on publicly available emission reports for many years, typically 16 quarterly reports for reactors in the USA 
and nine annual reports for reactors in the EU. For NPPs for which emission reports are available, the emission inventory is calculated based on the average over all reports pertaining to the same reactor unit taking into account the possible changes in operation of the corresponding NPP between the reported period and 2007. For NPPs for which no available reports could be found, a standard annual release is estimated based on the arithmetic average of the emission inventory of NPPs having emission reports.

The results of Kalinowski and Tuma (2009) are supposed to be valid for a generic year. Gueibe et al. (2017) adapts them to the situation in 2014 by taking the operational status of the NPPs in 2014 into consideration. The numbers of operational reactor units per site is retrieved from the IAEA (2015) database. The emission estimation for new reactors that were not in operational prior to 2007 is based on the calculated standard annual release per reactor in Kalinowski and Tuma (2009).

This paper provides two enhancements:

a. Replacing the estimates for a generic year by the reported real releases for 2014 wherever available.

b. Breaking down the time resolution from one year to reflect the operational time on a daily basis.

Otherwise, this paper treats all reactors most consistent with Kalinowski/Tuma (2009) in order to remain comparable to that initial global emission inventory. Many publications are based on that emission inventory and any change presented in this paper is done consistently for all reactors rather than optimized for individual reactors for which specific information is available. Only well-defined deviations are undertaken that are transparent. Possible enhancements for individual reactors are not undertaken for the sake of keeping the global emission inventory optimized and comparable to the previous studies. All data are made available in supplementary material in order to facilitate further customized refinements as desired.

\section{Publicly Available Reports of Nuclear Power Plants in 2014 and the Standard Annual Release}

Quarterly and annual radioactive gaseous effluent release reports of the NPPs in USA and European were taken into account in this work. The United States Nuclear Regulatory Commission's Radioactive Effluent and Environmental Reports database (U.S.NRC 2019) and the European Commission's Radioactive Discharges Database (RADD 2019) are used to obtain the reported radioxenon emissions data from NPPs in the year 2014.

A total of 390 nuclear power reactors on 174 sites were operating in 30 countries in 2014, 131 of them in 14 countries in Europe, 99 of them in the USA, 32 of them in the Russian Federation. Throughout 2014, all 48 available reactors were kept shut down in Japan. The current status of NPP operations in Japan is available from the JANTI (2020) and every NPP operator publishes the radioactivity release information on their homepage.

Figure 1 shows the development of NPPs from 2000 to 2019 both with regard to the number of units as well as with regard to their total capacity in $\mathrm{GW}_{\mathrm{e}}$. The number of reactors remains relatively stable and the capacity has increased over the decade by about $10 \%$.

Figure 2 shows the coordinates of all operational NPPs in 2014, the IMS noble gas systems and MIPFs. The reported data from 227 NPPs (59\% of 390 NPPs) are used in this study and shown with filled circles on the map. The coordinates of NPPs in the USA and the EU having reported radioxenon releases data in gaseous effluents are shown in Figs. 3 and 4, respectively.

The NPPs have two potential pathways of radioactive releases. These are the liquid and gaseous radioactive effluents. The contribution of radioxenon releases in liquid effluents is negligible. Only very few reports on radioxenon content in liquid releases are available. Based on these reported data, it is obvious that all activities in the liquid effluents are less than the activities in gaseous effluents by at least three orders of magnitude. In this study, the radioxenon data in each reactor unit were collected from the gaseous continuous and batch effluents to calculate the total radioxenon release from the site. 


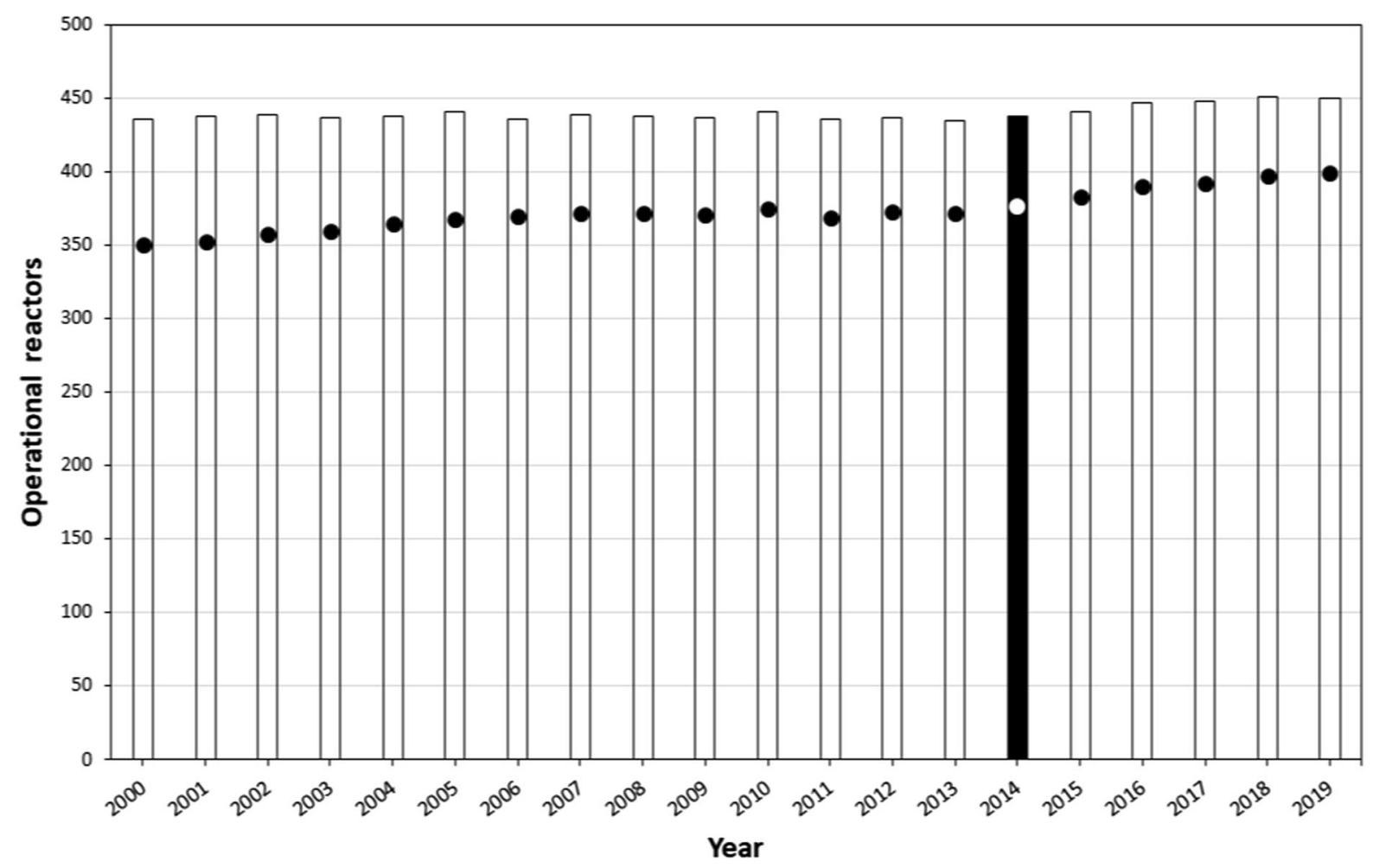

Figure 1

Development of NPPs from 2000 to 2019. Histogram bars indicate the number of units with the reference year 2014 highlighted in black, dots show their total capacity in GWe. The scale of the y-axis applies to both

Reports of NPPs in the USA separate continuous releases from batch releases. Since the time of the batch releases is not specified, their activities are added here to continuous releases. For NPPs involving more than one reactor unit located at the same site, the data for each reactor unit is available in the radioactive effluent and environmental reports of the USA NPPs. The reported data from individual reactor units were aggregated to calculate the total emission from each site.

The activity from continuous and batch releases are not distinguished in the EU database. The information included in the RADD reports provides the total radioxenon activity from each reactor unit and is aggregated here by NPP site.

The release reports show that there is huge variability. Even for the very same reactor unit the changes from 1 year to another are often by orders of magnitude. The averages over many years smooths out this uncertainty and provide a standard emission that establishes a best estimate. Therefore, for all reactors without emission reports, the standard annual release is used as calculated by Kalinowski and Tuma (2009). As a result, for the global emission inventory, the most accurate estimate is achieved by using these standard emission rates in case no reports are available. The result optimized for the reference year 2014 will still be a fairly good estimate for other years, because the total number of reactor units is fairly stable over the past two decades (see Fig. 1). For example, in 2019 there were 450 reactor units with a total capacity of $398.9 \mathrm{GW}_{\mathrm{e}}$ compared to 438 reactors with $376.3 \mathrm{GW}_{\mathrm{e}}$.

\section{Method for Deriving Monthly and Daily Emissions for NPPs}

In order to create the radioxenon emission inventory of NPPs in 2014, the reported release data 


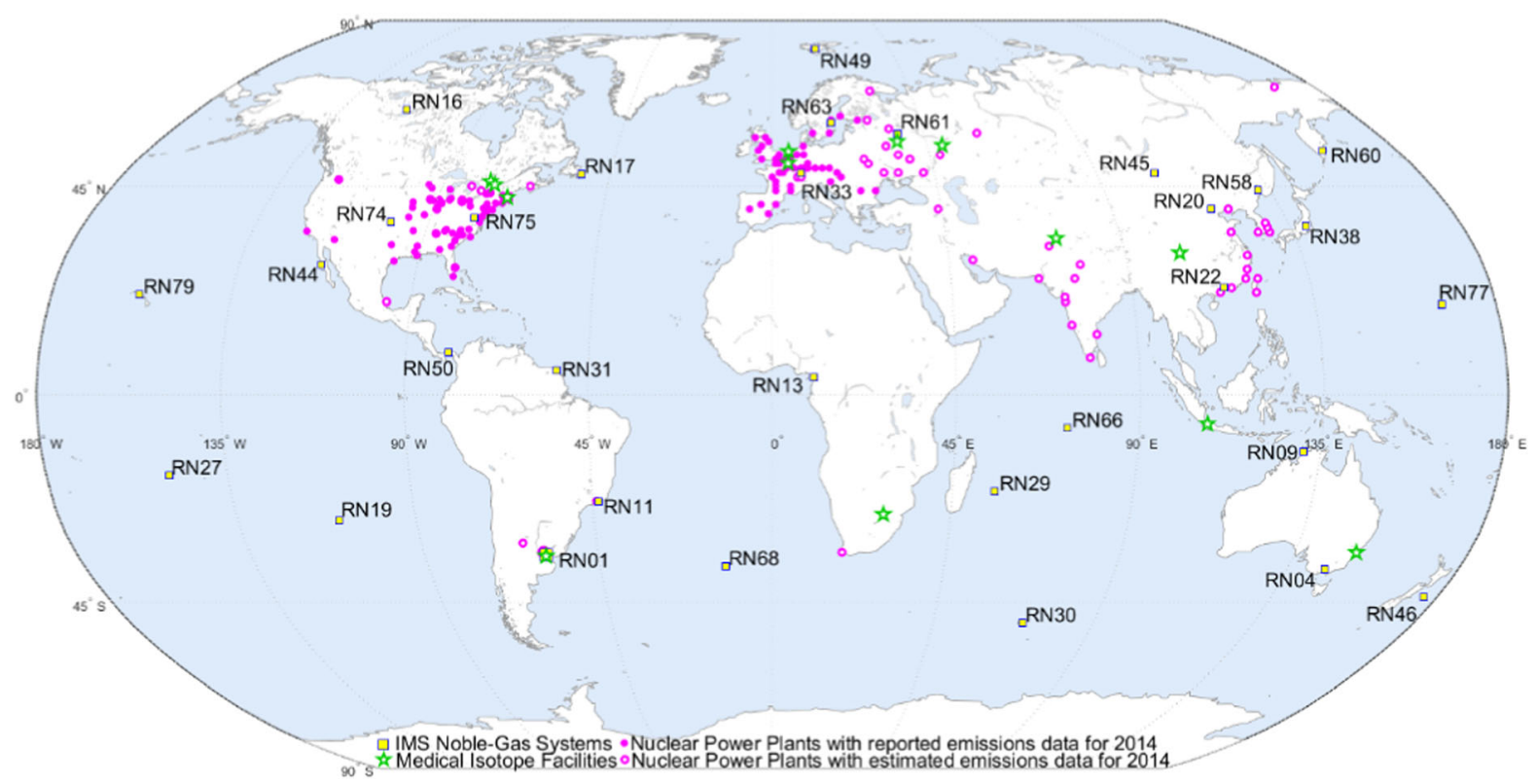

Figure 2

Location of the IMS noble gas systems and main sources discharging radioxenon fission products into the atmosphere. Stars indicate the MIPFs, empty circles indicate the NPPs without reported emission data, filled circles indicate the NPPs with reported data for 2014

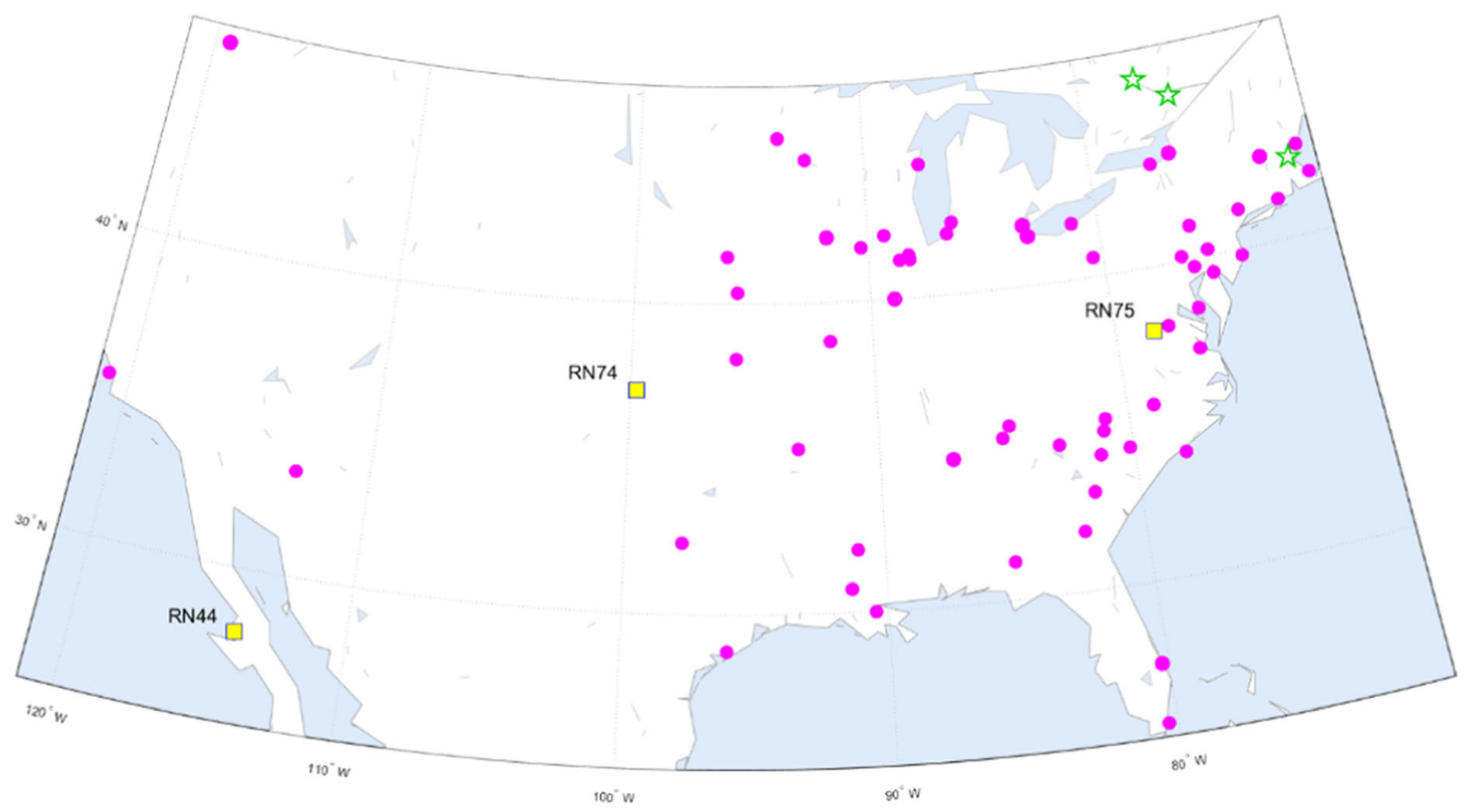

Figure 3

Operational NPPs in the USA during 2014. Reports about radioxenon emissions in 2014 are available for all of them 
(annual reports for European reactors, quarterly reports for the USA) are used and merged with the available information about the operational status of the reactors. The Power Reactors Information System (PRIS) database developed and issued by the IAEA contains information about the monthly operation factor of all nuclear power reactors in 2014 (IAEA 2015). Radioxenon release activities may depend among other parameters on the operation factor of the NPPs. It has been shown by Kalinowski et al. (2005) that out of the eight investigated reactor parameter half of them shows a correlation with ${ }^{133} \mathrm{Xe}$ releases. These are the number of reactor units for which effluent reports are available (this is fully reflected here), the design power (not used here), the fuel inventory (not used here) and the cladding thickness (not used here). Experience tells that the factor dominating the amount of radioxenon release is the integrity of the fuel cladding. Even tiny cracks can cause the radioxenon release to surge by several orders of magnitude overriding any other possible dependency on reactor parameters that influence the release rate. Based on the quarterly reports available for US NPPs, Fig. 5 demonstrates the relationship between the operating factor and the release of ${ }^{133} \mathrm{Xe}$. The expected increase of emissions with the duration of operation can be seen for some reactors whereas others show even the highest release in a quarter that has the smallest operating factor. This may be explained by the fact that a single release dwarfing the cumulated annual continuous release can occur during the process of shutting down or ramping up the power. Nevertheless, the reported or estimated annual release values are distributed over the year according to the up and down-time of the reactor. This is based on the reasonable assumption that the radioxenon emission is significantly lower for most of the time when the reactor is not producing power. Using the PRIS database, the information on ${ }^{131 \mathrm{~m}} \mathrm{Xe}$, ${ }^{133 \mathrm{~m}} \mathrm{Xe},{ }^{133} \mathrm{Xe}$ and ${ }^{135} \mathrm{Xe}$ release for each NPP site (aggregating all units at the same site) for every month has been created for 2014. The activity releases are presented down to a daily resolution according to the availability of downtimes with a higher granularity.

The operation factor is sometimes referred to as capacity factor. It is the ratio of the online time duration and a reference time duration and expressed as percentage. Practically this is independent from the operation power level. The operation factor $O F$ is calculated by $O F=(t / T) 100$ where $t$ is the number of hours on-line and $T$ is the number of hours in the reference period.

Radioxenon releases from the NPPs were calculated with the following equations: $R_{m}=\frac{(O F)_{m}}{(O F)_{a}} \frac{R_{t}}{12}$ for the monthly release activity and $R_{d}=\frac{(O F)_{m}}{(O F)_{a}} \frac{R_{t}}{365}$ for the daily release activity where $R_{t}$ is the total release for the whole year. $(O F)_{m}$ is the monthly operation factor and $(O F)_{a}$ is the average operating factor. Figure 6 shows the time-dependent average operating factors of all NPPs according to the IAEA database. The data are not presented in this article due to large number of entries but they are available in the supplementary material. Average operating factors of the USA NPPs and EU were $91.7 \%$ and $83.6 \%$ in 2014, respectively.

For a site with multiple units, first the monthly OFs are determined for each individual NPP unit. The average $\mathrm{OF}$ of all units gives the $\mathrm{OF}$ for the whole site. The release per month is calculated with the average OF of all units on that site multiplied with total radioxenon release of that site.

If no information about the individual radioxenon releases in 2014 is available and if the reactor was in operation during the year 2014, the standard

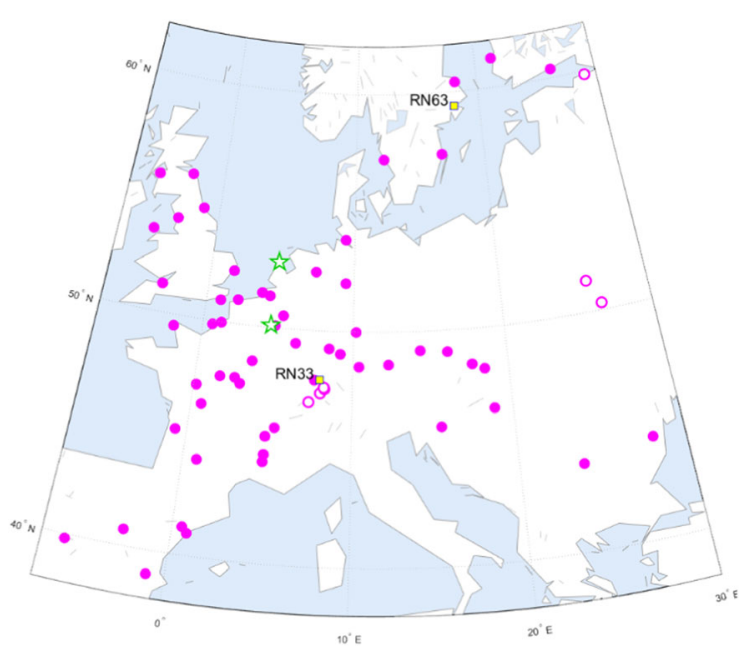

Figure 4

Operational NPPs in Europe during 2014. Empty circles indicate the NPPs without reported emission data. Filled circles indicated NPPs with reported radioxenon emissions in 2014 
radioxenon release for a generic year was taken into account in the calculations according to Kalinowski/ Tuma (2009).

Nine NPPs in EU have no specific information about radioxenon releases. Instead, the total noble gas emissions in 2014 are reported. The nine reactors with their total noble gas emission in brackets are Doel (8.25E + 10 Bq/day), Trillo-1 (7.10E + $08 \mathrm{~Bq} /$ day $)$, Tihange $(1.54 \mathrm{E}+10 \mathrm{~Bq} /$ day $)$, Cernavoda $(2.29 \mathrm{E}+09 \mathrm{~Bq} /$ day $)$, Dungeness $(2.44 \mathrm{E}+$ $10 \mathrm{~Bq} /$ day), Hunterston $(3.29 \mathrm{E}+10 \mathrm{~Bq} /$ day $)$, Torness $\quad(1.33 \mathrm{E}+10 \mathrm{~Bq} / \mathrm{day}), \quad$ Sizewell $\mathrm{B}$ $(8.41 \mathrm{E}+09 \mathrm{~Bq} /$ day $)$ and Wylfa-1 $(2.36 \mathrm{E}+$ $10 \mathrm{~Bq} /$ day). These sum up the activity of all radioactive argon, krypton and xenon. These data can be used for quality control purposes as upper release limit for radioxenon isotopes. A comparison of data shows that the total estimated radioxenon releases from the NPP sites Tihange $(2.29 \mathrm{E}+10 \mathrm{~Bq} /$ day according to the best estimate for a generic year for each unit), Cernavoda $(1.53 \mathrm{E}+10 \mathrm{~Bq} /$ day $)$ and Torness $(1.53 \mathrm{E}+10 \mathrm{~Bq} /$ day $)$ reactors are in fact higher than the total noble gas releases as reported for the same sites. The 2014 release of these reactor sites are obviously overestimated by the standard release estimates for a generic year.

The released ${ }^{133} \mathrm{Xe}$ activities were below the lower limit of detection (LLD) at Olkiluoto and Emsland nuclear power plants and not even the LLD value was reported. Unfortunately, it is not possible to derive a minimum detectable daily release value from the LLD. For the Olkiluoto NPP, even the total noble gas release was below LLD. For the Emsland NPP, the release of ${ }^{41} \mathrm{Ar}$ was $4.1 \mathrm{E}+08 \mathrm{~Bq} /$ day and the total noble gas release was reported with the same value. Therefore, the radioxenon release rates are definitely below the standard data for a generic year. In case of unknown data, the value could either be set to zero or a standard release could be used as appropriate. The latter is done in this paper.

Vermont Yankee had an operation factor of $99.8 \%$ but the radioxenon activity released from the plant stack was not reported in 2014 because the release rate was below the lower limit of detection and not even the LLD value was reported. Similarly, radioxenon fission gases were below the detectable limit at Browns Ferry, while the average operation factor of the three units was 93.6\%. Radioxenon concentrations released in gaseous effluents from the Clinton and Nine Mile Point with operation factors of $98.4 \%$ and $94.2 \%$, respectively, were not reported in 2014 because these were also below the lower limit of detection $(<1.00 \mathrm{E}-04 \mu \mathrm{Ci} /$ cc, i.e. $<3.7 \mathrm{kBq} / \mathrm{m}^{3}$ for both). ${ }^{133} \mathrm{Xe}$ activities were also below the same value for the lower limit of detection at Duane Arnold and Columbia. Only ${ }^{135} \mathrm{Xe}$ activity release from the Seabrook NPP was reported as $9.78 \mathrm{E}+07 \mathrm{~Bq} /$ year, the other radioxenon isotopes activities which were not reported were below the lower limit of detection.

\section{Summary of Results and Comparison to Previous Best Estimates}

The daily activity release is calculated for every NPP as the distribution of the total reported annual release over the fraction of the year for which the NPP is reported to have been in operations in 2014. The global ${ }^{133} \mathrm{Xe}$ emission inventory for all NPP sites is visualized in Fig. 7. It shows clearly minimum values for all periods when a NPP was off-grid or when the release value was very low. Only very few reactors reach the highest values that and can be identified as lines of the dark blue colour.

The black histogram bars in Fig. 8 show the ${ }^{133} \mathrm{Xe}$ emission for all European NPPs ordered by the amount according to the best estimate of Kalinowski/ Tuma (2009) and the red bars show the reported emissions for the year 2014. This comparison demonstrates the difference between the real emission and the best estimates with all but twelve cases having reported lower emissions than the best estimate. The difference was up to four orders of magnitude while the overall spread of reported emissions was five orders of magnitude. The biggest underestimation of the best estimate was only one order of magnitude.

Figure 9 provides the same kind of comparison for the NPPs in the USA. The observation is very similar as for the NPPs in the Europe. For the USA, the best estimate is an overestimation for all but 10 NPP sites. The largest overestimation is four orders of magnitudes above the reported emission. All 


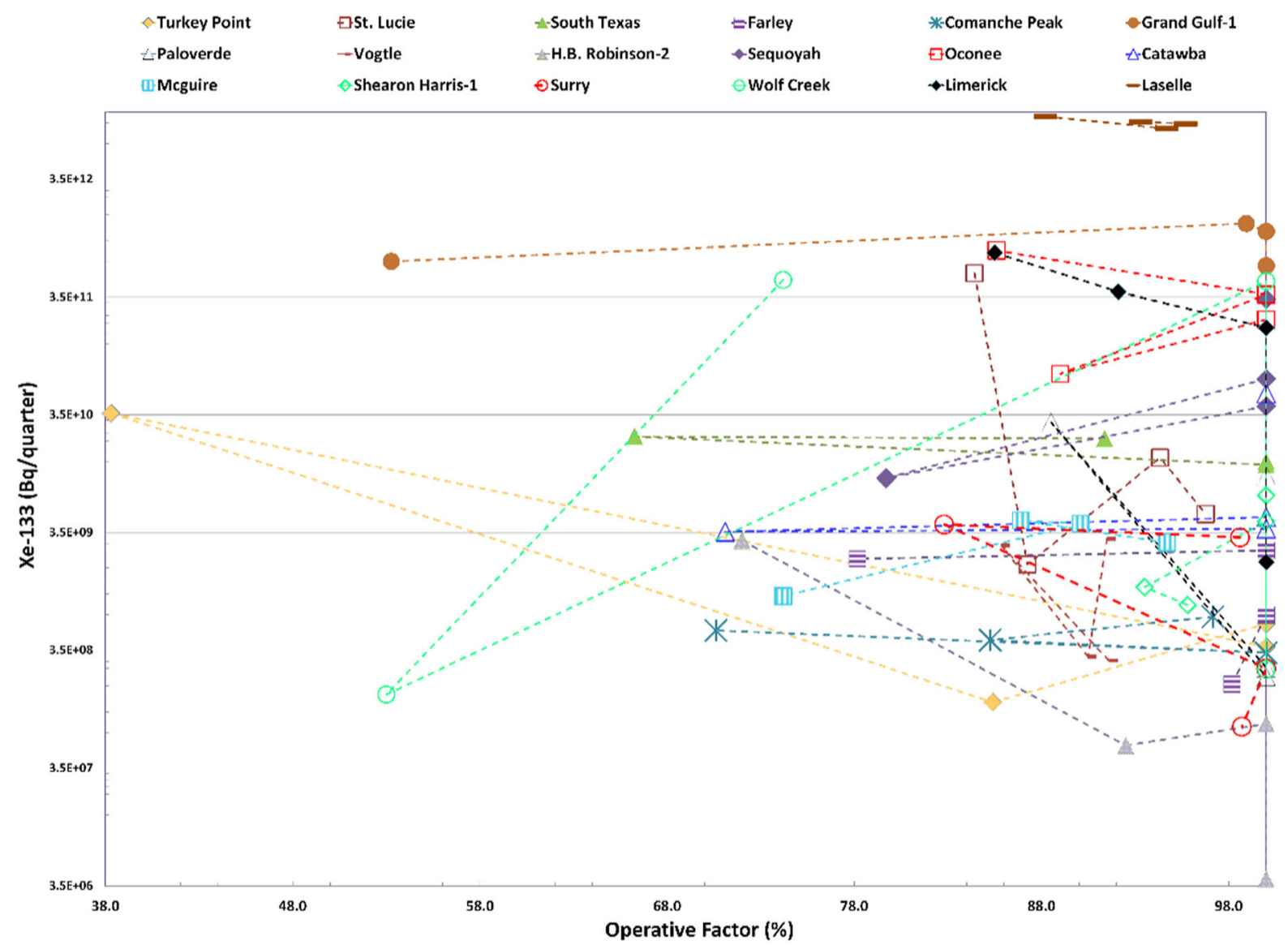

Figure 5

Relationship of quarterly 133 Xe releases and the operating factor in the same quarter for all US NPPs for which this information is available for all four quarters of 2014

estimated values spread over six orders of magnitude and the reported values cover five orders of magnitude.

Even though, the best estimate emissions from individual reactor sites are apparently rarely close to the reality the statistical distribution of releases without taking the specific reactor into consideration is not as bad and the total best estimate summed up over a whole region is less than one order of magnitude off.

The total reported ${ }^{133} \mathrm{Xe}$ emission from the USA NPPs was $1.75 \mathrm{E}+11 \mathrm{~Bq} /$ day. This includes $1.56 \mathrm{E}+11 \mathrm{~Bq} /$ day from PWRs and $1.86 \mathrm{E}+10 \mathrm{~Bq} /$ $\mathrm{d}$ from BWRs. It should be noted that the Lasalle reactor site has high activity of ${ }^{133} \mathrm{Xe}$ $(1.17 \mathrm{E}+11 \mathrm{~Bq} /$ day $)$ compared to the other NPPs even though there were no batch releases. That reactor alone accounts for two thirds of all ${ }^{133} \mathrm{Xe}$ emission of NPPs in the USA.

The total ${ }^{133} \mathrm{Xe}$ activity adding up to $6.05 \mathrm{E}+11 \mathrm{~Bq} /$ day when using the generic annual release estimates of Kalinowski/Tuma (2009). This is an overestimation compared to the reported data by a factor of 3.5. For the NPPs in EU, 133-Xe emission activity from the data reported for 2014 is $1.91 \mathrm{E}+11 \mathrm{~Bq} /$ day. This is an overestimation by a factor of 2.5 compared to the activity estimated for a generic year of $4.84 \mathrm{E}+11 \mathrm{~Bq} /$ day.

In addition of the above mentioned nuclear power plants, the published data are available for Korean nuclear power plants for the year 2014 (Tae Young Kong et. al., 2017). The data include total activity $(8.86 \mathrm{E}+10 \mathrm{~Bq} / \mathrm{day}$ adding up the data of all four 


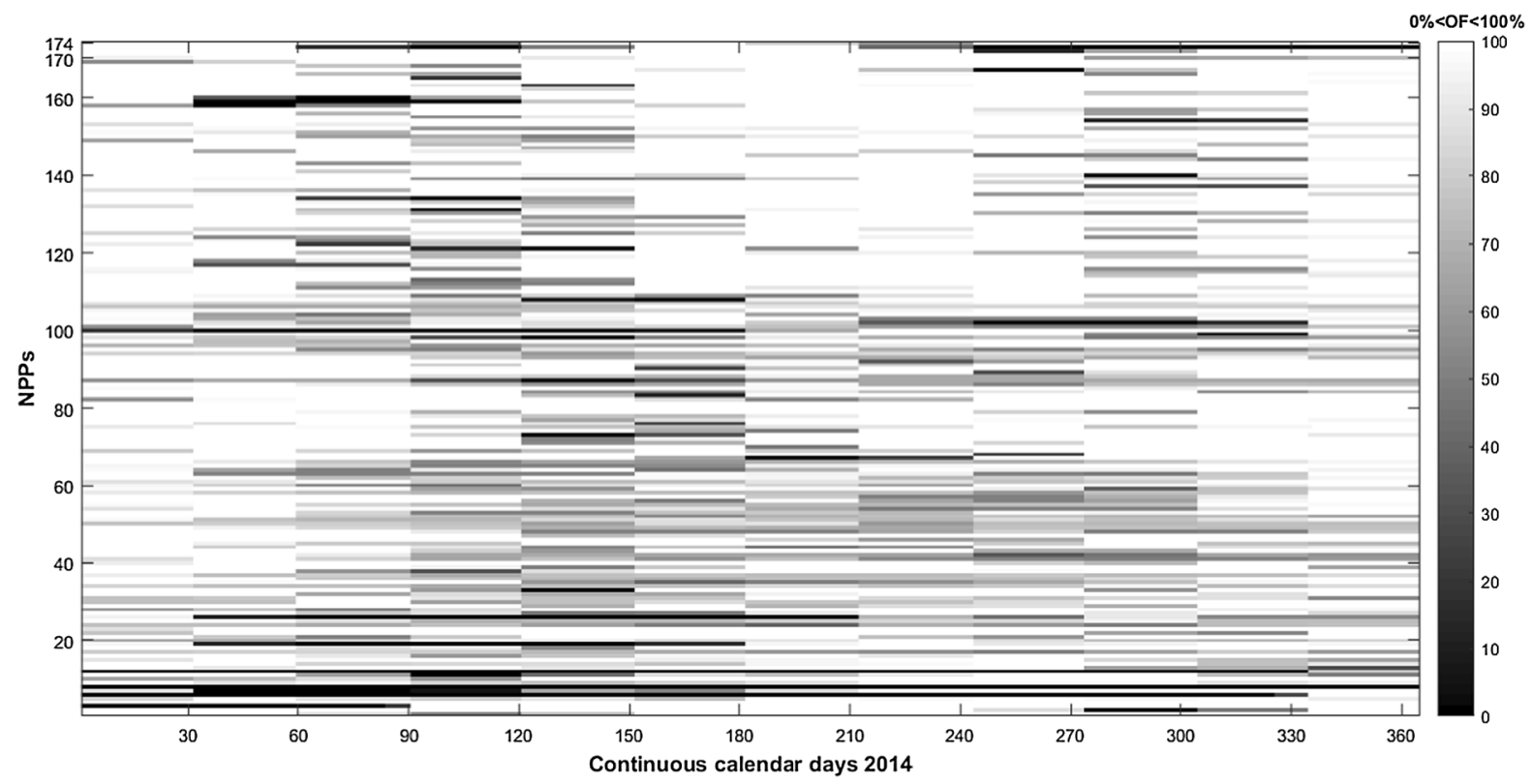

Figure 6

Visualization of the operating factors for all NPPs in 2014. Each line is representing one NPP and the column structure represents the months. The exact data are available in the supplementary material

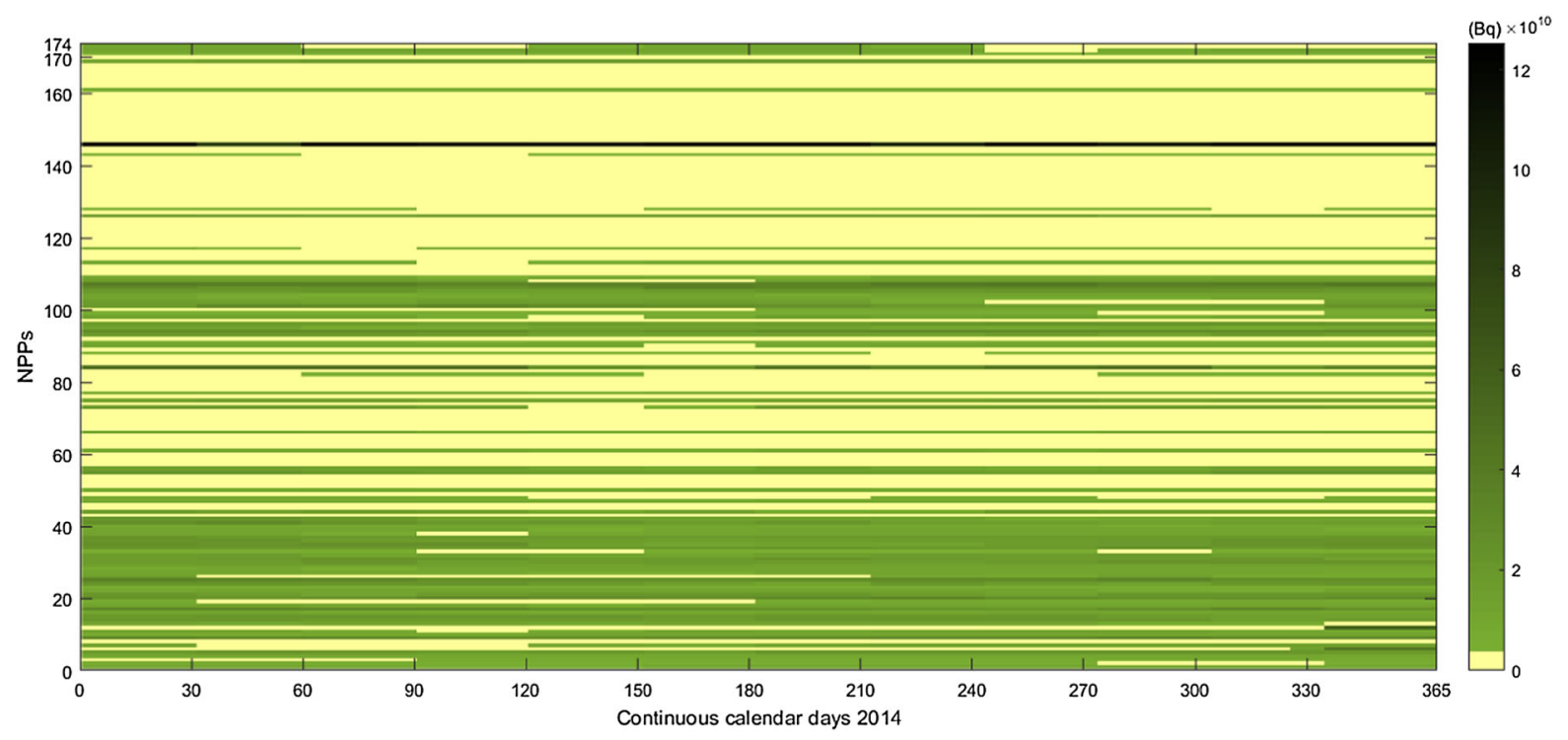

Figure 7

Visualization of the daily ${ }^{133}$ Xe release value for all NPPs in 2014. Each line is representing one NPP and the column structure represents the months. The exact data are available in the supplementary material. The color bar on the right side shows the spread of colors from lowest to highest release values 


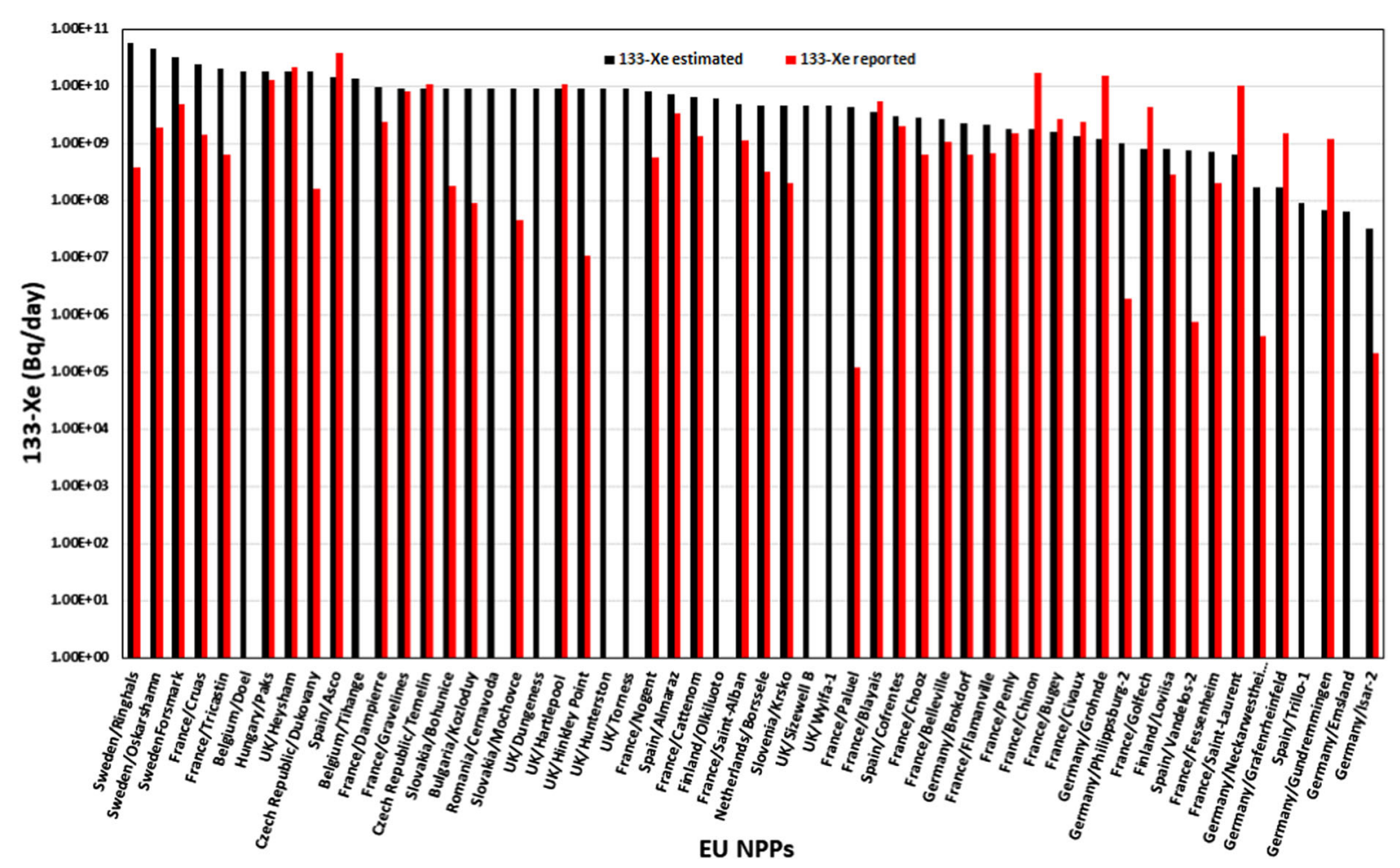

Figure 8

Comparison of estimated and reported 133-Xe activity for 56 nuclear power plants (42 PWR, 5 BWR, 7 GCR and 1 PHWR) in Europe ordered by decreasing estimated release amounts for a generic year (black) and compared with the reported releases in the year 2014 (red)

NPPs) of argon, krypton and xenon from four NPPs, as illustrated in Fig. 10. It is clearly seen that the total estimated ${ }^{133} \mathrm{Xe}$ activities alone $(1.76 \mathrm{E}+11 \mathrm{~Bq} /$ day for all four NPPs together) is about a factor of two higher than the total reported noble gases activities of these four NPPs. Obviously, these reactors have put retention technologies in place that allow short-lived noble gas isotopes to decay before the gas is released to the atmosphere. A conservative estimate for the release from the Korean NPPs was made by assuming that the four radioxenon isotopes sum up to the reported total noble gas emissions, where the share of each radioxenon isotope is determined according to the isotopic ratios of the best estimate given by Kalinowski/Tuma (2009).

The global radioxenon emission inventory including both estimated and reported are shown in Table 1. This global inventory is the most realistic ever published for a specific year, because $37 \%$ $\left({ }^{131 \mathrm{~m}} \mathrm{Xe}\right), \quad 36 \%\left({ }^{133 \mathrm{~m}} \mathrm{Xe}\right), \quad 56 \%\left({ }^{133} \mathrm{Xe}\right)$ and $53 \%$ $\left({ }^{135} \mathrm{Xe}\right)$ of the data used in the calculations are based on reported radioxenon emissions of 227 NPPs out of a total of 390 units at 174 NPP sites in 2014.

The paper of Gueibe et al. (2017) uses an emission inventory that is a first simple update to Kalinowski/Tuma (2009). It still uses estimates for a generic year but takes into account which reactor were in operation in 2014. Therefore, it is used as reference for comparison. The Table 2 compares the results for Europe and North America obtained for the estimated radioxenon releases in a generic year with those calculated from estimated and data reported in 2014 emission of radioxenon presented in this study. Whereas, the total global emission inventory of ${ }^{133} \mathrm{Xe}$ and ${ }^{135} \mathrm{Xe}$ from NPPs as determined in this study is less than the estimates of Gueibe et al. (2017) by $33 \%$ and $56 \%$ respectively, ${ }^{131 \mathrm{~m}} \mathrm{Xe}$ remains almost the same (globally $2.5 \%$ less) 


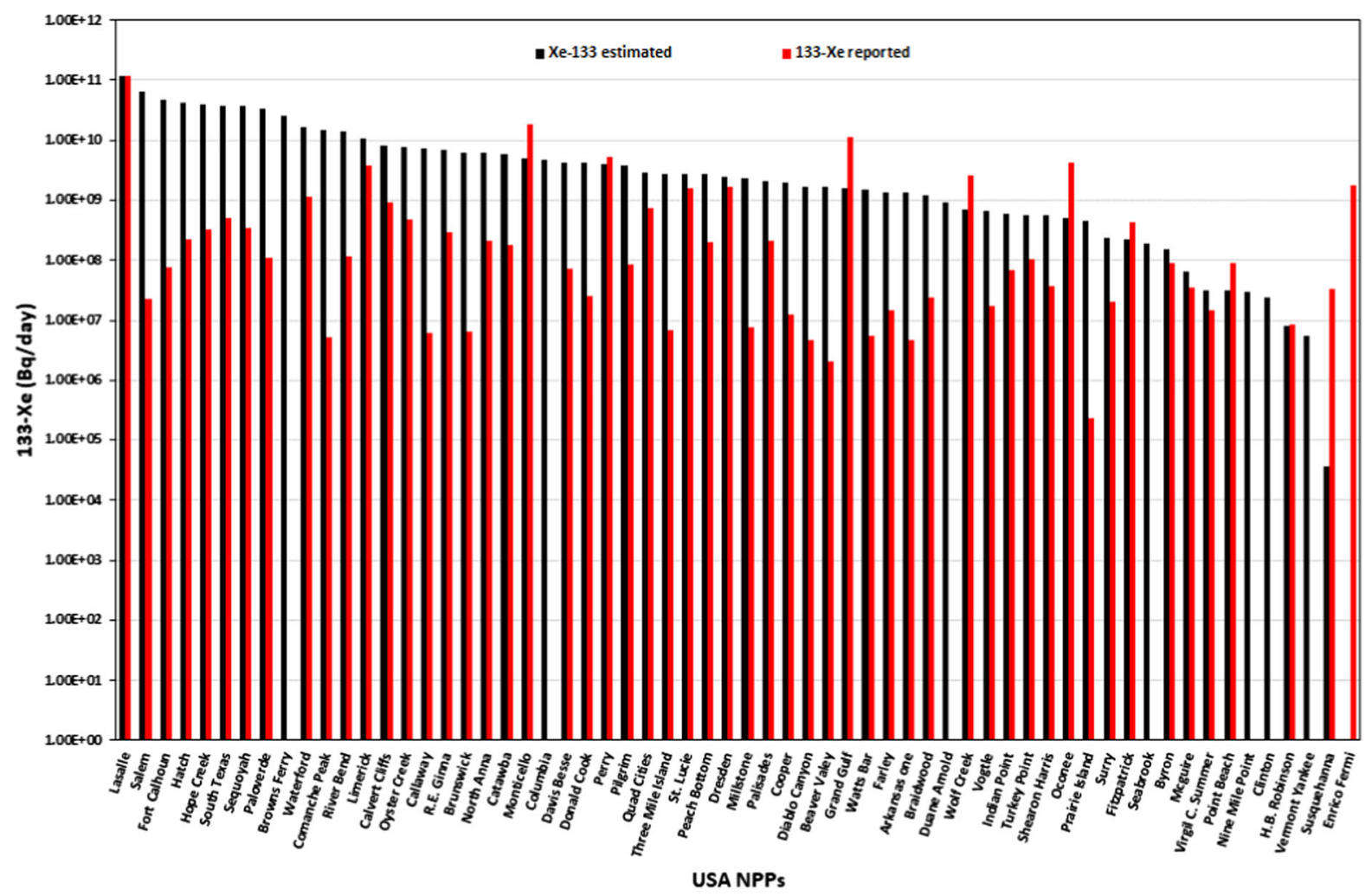

Figure 9

Comparison of estimated and reported 133-Xe activity for 62 nuclear power plants (38 PWR and 24 BWR) in USA ordered by decreasing estimated release amounts for a generic year (black) and compared with the reported releases in the year 2014 (red)

and ${ }^{133 \mathrm{~m}} \mathrm{Xe}$ is found at a slightly higher amount (17\% increase).

\section{Probability Density Functions}

The strong variation of radioxenon releases found for individual NPPs as demonstrated in the previous section raises the question about what should be used as best estimate for the release assumption of a specific NPP in case no reported release information is available. Rather than using the best estimate as provided by Kalinowski/Tuma (2009), it is recommended to use the empirical release data of a large number of NPPs to determine a probability density function (PDF). If a precise number is required, the logarithmic median value of the distribution can be used; in case of a log-normal distribution the logarithmic mean.
Figure 11 shows the distribution of all annual releases from NPPs in Europe and the USA as reported for 2014. The releases are presented in logarithmic scale because they spread over many orders of magnitude. A Gaussian shape is fitted to the distribution of all isotopes except for ${ }^{131 \mathrm{~m}} \mathrm{Xe}$ for which the annual releases do not exhibit a log-normal distribution. The fitting curve parameters are provided in Table 3.

The probability density functions provided here can be used in the Bayesian inferential methodology for characterizing a source of radioxenon and determine the probability that a certain observation is related to a NPP (Yee et al. 2014; Eslinger et al. 2016). The set of prior parameters includes the known location and probability of the source strength. If source-receptor sensitivities between a specific NPP site and the radionuclide station location are also taken into consideration as contextual information, the posterior probability of that specific NPP site having contributed with a certain share to the 
Estimated total radioxenon $\quad$ Noble gas published

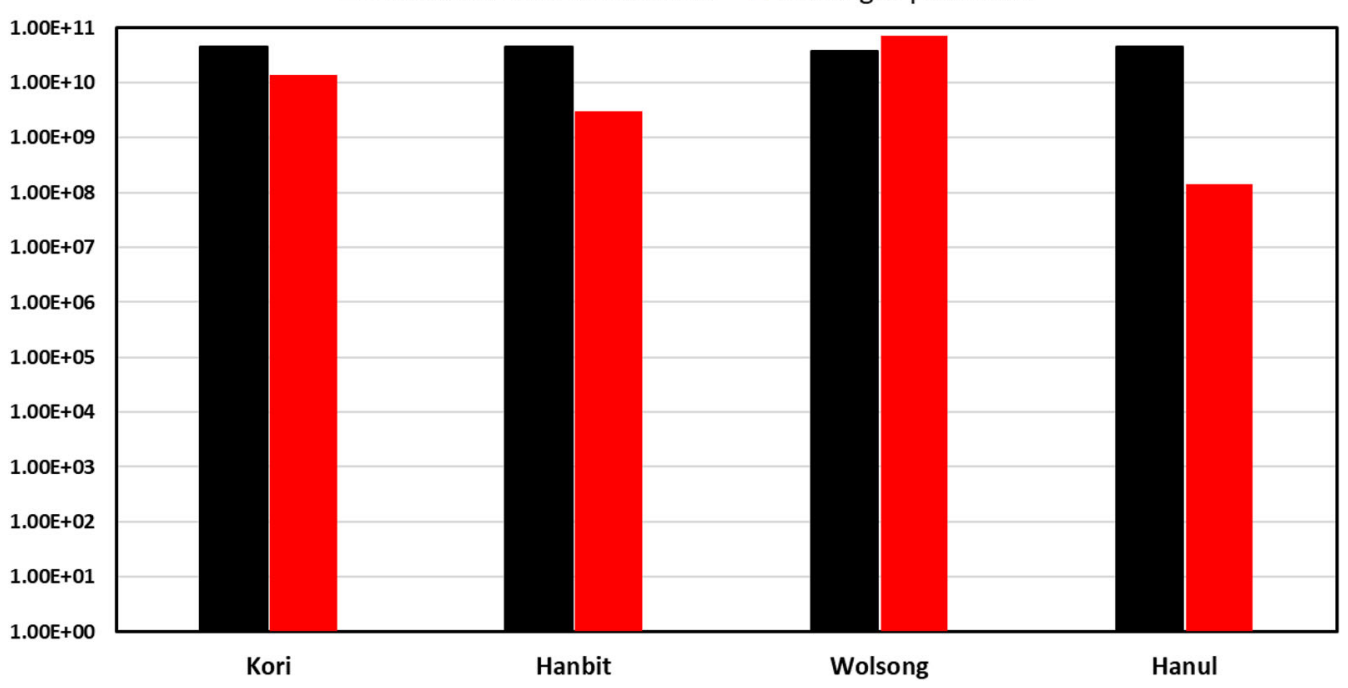

Figure 10

Comparison of the estimated ${ }^{133} \mathrm{Xe}$ and releases of total radioactive noble gases (argon, krypton and xenon) from Korean NPPs

observation in question can be inferred. In the past, the prior distributions used typically assume a uniform prior distribution between a lower and upper bound for the emission rate with the minimum being set to zero and the upper bound derived from an educated guess about a reasonable maximum release (Yee et al. 2014). Eslinger et al. (2019) make use of the ratios of all four CTBT relevant radioxenon isotopes assuming certain precise release ratios calculated as synthetic data for specific scenarios. By varying certain parameters like irradiation time of isotope breeding targets, a certain range of prior values is covered. This paper suggests using the lognormal distribution for all CTBT relevant radioxenon isotopes from a large number of reported releases of the same source or of similar facilities as the prior distribution.

\section{Summary and Conclusions}

This paper presents the most precise global emission inventory of NPPs for a specific year. It is based on the operating factors of $100 \%$ and the reported release data from 59\% (227) of all 390 NPP units that were in operation in 2014 . The results show that there is a significant difference between the radioxenon emission data for a generic year available in the literature and emission inventory based on the available reported data of NPPs in 2014. On the global scale, the total estimated emissions are fairly robust and show an overall decline for ${ }^{133} \mathrm{Xe}$ and ${ }^{135}$ Xe by $33 \%$ and $56 \%$ respectively but no significant difference for the two isomers. However, when it comes to individual facilities the best estimates for a generic year are not reliable at all. They can deviate by many orders of magnitude.

More real release reports would make the emission inventory more accurate. Having total emission data for specific years and quarters is useful. However, this is a very low time resolution. Due to the high variability of emission, it would be significantly more meaningful to have release data on a daily basis or with even higher time resolution. If such precise data are not available, for best estimates of individual NPPs, it is recommended to use probability density functions as derived in this paper from all reported emissions. It should be noted that these are still crude assumptions because the time resolution of one year doesn't reflect the high variability of the emission pattern over time, specifically the batch releases. 

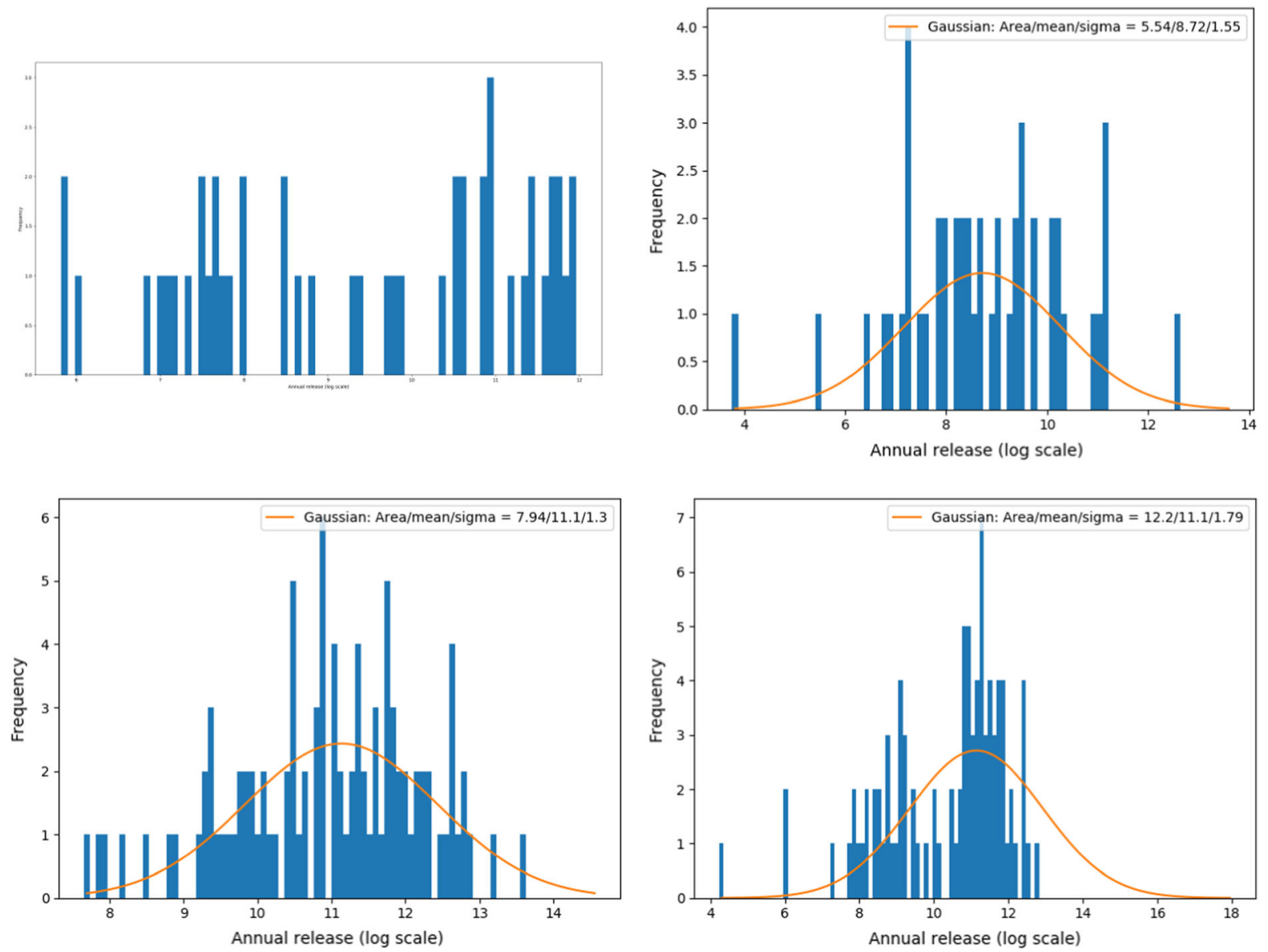

Figure 11

Gaussian fits on the distribution of reported annual releases from NPP in logarithmic scale. Top left: ${ }^{131 \mathrm{~m}} \mathrm{Xe}$; top right: ${ }^{133 \mathrm{~m}} \mathrm{Xe}$; bottom left: ${ }^{133} \mathrm{Xe}$; bottom right: ${ }^{135} \mathrm{Xe}$

Table 1

Radioxenon emission inventory by continent

\begin{tabular}{|c|c|c|c|c|}
\hline \multirow[t]{2}{*}{ Continents } & \multicolumn{4}{|l|}{ Radioxenon } \\
\hline & $\begin{array}{l}{ }_{\text {year })}^{131 \mathrm{~m}} \mathrm{Xe}(\mathrm{Bq} / \\
\end{array}$ & $\begin{array}{l}{ }^{133 m} \mathrm{Xe}(\mathrm{Bq} / \\
\text { year })\end{array}$ & $\begin{array}{l}{ }^{133} \mathrm{Xe}(\mathrm{Bq} / \\
\text { year) }\end{array}$ & $\begin{array}{l}{ }^{135} \mathrm{Xe}(\mathrm{Bq} / \\
\text { year })\end{array}$ \\
\hline Africa & $2.26 \mathrm{E}+11$ & $7.41 \mathrm{E}+10$ & $3.41 \mathrm{E}+12$ & $1.86 \mathrm{E}+12$ \\
\hline Asia & $9.14 \mathrm{E}+12$ & $3.00 \mathrm{E}+12$ & $1.36 \mathrm{E}+14$ & $7.56 \mathrm{E}+13$ \\
\hline Europe & $1.73 \mathrm{E}+13$ & $4.39 \mathrm{E}+12$ & $1.84 \mathrm{E}+14$ & $8.29 \mathrm{E}+13$ \\
\hline $\begin{array}{l}\text { North } \\
\text { America }\end{array}$ & $1.04 \mathrm{E}+13$ & $9.86 \mathrm{E}+12$ & $1.17 \mathrm{E}+14$ & $4.40 \mathrm{E}+13$ \\
\hline $\begin{array}{l}\text { South } \\
\text { America }\end{array}$ & $5.65 \mathrm{E}+11$ & $1.85 \mathrm{E}+11$ & $8.52 \mathrm{E}+12$ & $4.66 \mathrm{E}+12$ \\
\hline Total & $3.76 \mathrm{E}+13$ & $1.75 \mathrm{E}+13$ & $4.49 \mathrm{E}+14$ & $2.09 \mathrm{E}+14$ \\
\hline
\end{tabular}

The global emission inventory of NPP for 2014 is complemented by a recent study on radioxenon release estimates for the global fleet of nuclear research reactors Kalinowski et al. (2020) and reported or estimated releases from medical isotope production facilities (MIPFs) to create a comprehensive global radioxenon emission inventory for 2014.

The global radioxenon emission inventory can be used for studies to estimate the contribution of this anthropogenic source to the observed ambient concentrations at IMS noble gas sensors to support CTBT monitoring activities, including calibration 
Table 2

Comparison of estimated and estimated and reported radioxenon emissions in 2014

\begin{tabular}{|c|c|c|c|c|c|}
\hline \multirow[t]{2}{*}{ Conti-nents } & \multirow[t]{2}{*}{ Estimated and reported } & \multicolumn{4}{|l|}{ Radioxenon } \\
\hline & & ${ }^{131 \mathrm{~m}} \mathrm{Xe}(\mathrm{Bq} /$ year$)$ & ${ }^{133 m} \mathrm{Xe}(\mathrm{Bq} /$ year $)$ & ${ }^{133} \mathrm{Xe}(\mathrm{Bq} /$ year $)$ & ${ }^{135} \mathrm{Xe}(\mathrm{Bq} /$ year $)$ \\
\hline \multirow[t]{2}{*}{ Europe } & Gueibe et al. (2017), estimated & $1.38 \mathrm{E}+13$ & $4.19 \mathrm{E}+12$ & $2.57 \mathrm{E}+14$ & $3.41 \mathrm{E}+14$ \\
\hline & 2014 increase due to real reports & $3.49 \mathrm{E}+12$ & $1.93 \mathrm{E}+11$ & $-7.38 \mathrm{E}+13$ & $-2.58 \mathrm{E}+14$ \\
\hline \multirow[t]{2}{*}{ North America } & Gueibe et al. (2017), estimated & $1.47 \mathrm{E}+13$ & $7.38 \mathrm{E}+12$ & $2.60 \mathrm{E}+14$ & $5.29 \mathrm{E}+13$ \\
\hline & 2014 increase due to real reports & $-4.34 \mathrm{E}+12$ & $2.45 \mathrm{E}+12$ & $-1.46 \mathrm{E}+14$ & $-8.95 \mathrm{E}+12$ \\
\hline \multirow[t]{2}{*}{ Total } & Gueibe et al. (2017), estimated & $3.85 \mathrm{E}+13$ & $1.49 \mathrm{E}+13$ & $6.69 \mathrm{E}+14$ & $4.77 \mathrm{E}+14$ \\
\hline & 2014 increase due to real reports & $-9.45 \mathrm{E}+11$ & $2.60 \mathrm{E}+12$ & $-2.21 \mathrm{E}+14$ & $-2.68 \mathrm{E}+14$ \\
\hline
\end{tabular}

Table 3

Statistical parameters for distributions of the logarithmic values of reported annual radioxenon releases from NPPs in Europe and the USA

Isotope Min Max Median Mean Sigma Best estimate (Bq/ year)

\begin{tabular}{lrrrlll}
\hline${ }^{131 \mathrm{~m}} \mathrm{Xe}$ & 5.8 & 12.0 & 9.8 & 9.4 & $\mathrm{n} / \mathrm{a}$ & $2.62 \mathrm{E}+09$ \\
${ }^{133 \mathrm{~m}} \mathrm{Xe}$ & 3.8 & 12.6 & 8.6 & 8.72 & 1.55 & $5.25 \mathrm{E}+08$ \\
${ }^{133} \mathrm{Xe}$ & 7.7 & 13.6 & 11.0 & 11.1 & 1.30 & $1.26 \mathrm{E}+11$ \\
${ }^{135} \mathrm{Xe}$ & 4.2 & 12.8 & 10.9 & 11.1 & 1.79 & $1.26 \mathrm{E}+11$ \\
\hline
\end{tabular}

and performance assessment of the verification system as described in the Treaty as well as developing and validating methods for enhanced detection capabilities of signals that may indicate a nuclear test.

\section{Acknowledgements}

We thank Boxue Liu and Peter Jansson for calculating the Gaussian distribution functions from the annual radioxenon release data.

\section{Funding}

Open Access funding enabled and organized by Projekt DEAL.

Disclaimer The views expressed herein are those of the authors and do not necessarily reflect the views of the CTBTO Preparatory Commission.

Open Access This article is licensed under a Creative Commons Attribution 4.0 International License, which permits use, sharing, adaptation, distribution and reproduction in any medium or format, as long as you give appropriate credit to the original author(s) and the source, provide a link to the Creative Commons licence, and indicate if changes were made. The images or other third party material in this article are included in the article's Creative Commons licence, unless indicated otherwise in a credit line to the material. If material is not included in the article's Creative Commons licence and your intended use is not permitted by statutory regulation or exceeds the permitted use, you will need to obtain permission directly from the copyright holder. To view a copy of this licence, visit http://creativecommons.org/licenses/by/4.0/.

Publisher's Note Springer Nature remains neutral with regard to jurisdictional claims in published maps and institutional affiliations.

\section{REFERENCES}

Achim, P., Generoso, S., Morin, M., Gross, P., Le Petit, G., \& Moulin, C. (2016). Characterization of Xe-133 global atmospheric background: Implications for the international monitoring system of the comprehensive nuclear-test-ban treaty. Journal of Geophysical Research: Atmospheres, 121(9), 4951-4966.

Eslinger, P. W., Lowrey, J. D., Miley, H. S., Rosenthal, W. S., \& Schrom, B. T. (2019). Source term estimation using multiple xenon isotopes in atmospheric samples. Journal of Environmental Radioactivity, 204, 111-116.

Eslinger, P. W., \& Schrom, B. T. (2016). Multi-detection events, probability density functions, and reduced location area. Journal of Radioanalytical and Nuclear Chemistry, 307(3), 1599-1605.

Gueibe, C., Kalinowski, M. B., Baré, J., Gheddou, A., Krysta, M., \& Kusmierczyk-Michulec, J. (2017). Setting the baseline for estimated background observations at IMS systems of four radioxenon isotopes in 2017. Journal of Environmental Radioactivity, 178, 297-314.

IAEA (2015). Operating experience with nuclear power stations in member states in 2014, (ISBN: 978-92-0-155015-6).

JANTI (2020). Japan Nuclear Technology Institute: Plant operating chart for last 12 months. https://www.gengikyo.jp/db/fm/ plantstatusE.php, Accessed on 3 March 2020. 
Kalinowski, M. B., Erickson, L. H., \& Gugle, G. J. (2005). Preparation of a Global Radioxenon Emission Inventory: Understanding Sources of Radioactive Xenon Routinely Found in the Atmosphere by the International Monitoring System for the Comprehensive Nuclear-Test-Ban Treaty. Arms Control Disarmament and International Security Research Report, University of Illinois. ACDIS Research Report ACDIS KAL:1.2005.

Kalinowski, M. B. (2011). Characterisation of prompt and delayed atmospheric radioactivity releases from underground nuclear tests at Nevada as a function of release time. Journal of Environmental Radioactivity, 102, 824-836.

Kalinowski, M. B., Grosch, M., \& Hebel, S. (2014). Global Xenon133 emission inventory caused by medical isotope production and derived from the worldwide technetium-99m demand. Pure and Applied Geophysics, 171(3), 707-716.

Kalinowski, M.B.; Tayyebi, P.; Lechermann, M. (2020). Global radioxenon emission inventory from nuclear research reactors. Submitted to pure and applied geophysics topical issue on nuclear explosion monitoring and verification: Scientific and technological advances.

Kalinowski, M. B., \& Tuma, M. P. (2009). Global radioxenon emission inventory based on nuclear power reactor reports. Journal of Environmental Radioactivity, 100, 58-70.

Kong, T. Y., Kim, S., Lee, Y., Son, J. K., \& Maeng, S. J. (2017). Radioactive effluents released from Korean nuclear power plants and the resulting radiation doses to members of the public. $\mathrm{Nu}$ clear Engineering and Technology, 49(8), 1772-1777.

RADD (2019). European Commission's RADD (Radioactive Discharges Database) https://europa.eu/radd/ (last Accessed on 23 December 2019)

U.S. NRC (2019). Radioactive Effluent and Environmental Reports: U.S.NRC homepage https://www.nrc.gov/reactors/ operating/ops-experience/tritium/plant-info.html (last Accessed on 23 December 2019)

Yee, E., Hoffman, I., \& Ungar, K. (2014). Bayesian inference for source reconstruction: A real-world application. International Scholarly Research Notices, 2014, 1-12.

(Received March 6, 2020, revised August 6, 2020, accepted August 20, 2020, Published online September 22, 2020) 